FORUM

\title{
Science, objectivity, and academic freedom in the twenty-first century
}

\author{
Rosemary A. Joyce (1) \\ Department of Anthropology, University of California, Berkeley, United States \\ Email: rajoyce@berkeley.edu
}

\begin{abstract}
The publication of a book in 2020 that argues against repatriation, on the grounds that it is incompatible with the necessary objectivity required for the production of scientific knowledge, raises issues that most scholars consider long settled. Rather than engage in a detailed review, this commentary revisits the reasons why claims of contributing to universal knowledge are insufficient to justify exploitation of the physical remains, and cultural property, of people who object to specific lines of research and reminds readers that academic freedom is a mitigated freedom that is rooted in responsibilities and norms agreed on within disciplines, all of which today accept repatriation as part of the necessary redress of legacies of exploitation.
\end{abstract}

Keywords: academic freedom; objectivity; repatriation; ethics; human subjects

In January 1999, approaching the end of a five-year term as director of the Museum of Anthropology at Berkeley, I presented a paper at the fourth World Archaeological Congress in Cape Town on what I had learned in that role about the challenges of coming to terms with anthropology museums' uncomfortable legacy. In the process of implementing the Native American Graves Protection and Repatriation Act (NAGPRA), museum anthropologists confronted the truth about how researchers historically treated members of Indigenous societies as objects of study, often including treatment inconsistent with practices that are part of modern considerations for "Responsible Conduct of Research." ${ }^{1}$ The history of objectification of the biological remains of Indigenous people as specimens, rendered available for scientific study without consideration of the impacts on the source communities and often without constraints of any kind, demanded reconsideration of research conduct. This was threatening to researchers used to being unquestioned. Yet, I argued, it was hardly unprecedented to place limits on science, as some researchers in the 1990s claimed in opposing implementation of NAGPRA.

I framed my conference presentation around the relationships between concepts of academic freedom and stewardship that were deployed in conflicts over repatriation by people with distinct interests - conflicts into which my four-and-a-half years leading the

\footnotetext{
${ }^{1}$ E.g., National Institutes of Health (NIH) 2020; Native American Graves Protection and Repatriation Act (NAGPRA), 16 November 1990, 104 Stat. 3048, https://www.govtrack.us/congress/bills/101/hr5237.

(C) The Author(s), 2021. Published by Cambridge University Press on behalf of the International Cultural Property Society. This is an Open Access article, distributed under the terms of the Creative Commons Attribution licence (http://creativecommons.org/ licenses/by/4.0/), which permits unrestricted re-use, distribution, and reproduction in any medium, provided the original work is properly cited.
} 
museum had plunged me. In the publication of that talk, I wrote about why we needed to reject the claim that an absolute right to academic freedom was undercut by the process of engagement that NAGPRA mandated:

[T]hose who invoke academic freedom in the context of the implementation of repatriation laws or broader based repatriation approaches are ignoring, for rhetorical effect, the actual nature of academic freedom.... Academic freedom is not an absolute right to study anything one wishes in any way one wishes. It is meant to be a guarantee that researchers will not be persecuted by those with power over them for the content of their research results. ${ }^{2}$

Yet here we are, two decades later, facing the same claim, elaborated in yet another book published by a scholarly press, a publication supposedly justified as advancing debate.

The fundamental argument made in Elizabeth Weiss and James Springer's book Repatriation and Erasing the Past is that consultation and collaboration with Indigenous peoples, whether required under NAGPRA or undertaken outside it, is contrary to academic freedom (sometimes rendered as "scientific freedom," a distinction addressed later). ${ }^{3}$ Thus, it is worth considering what academic freedom is and is not. Joan Scott has reviewed the history of the concept from its formative moments in early twentieth-century US universities. ${ }^{4}$ She makes clear that academic freedom is a form of freedom of speech, justified because of the contribution academic freedom makes to the common good. To articulate opinions noxious to political and economic powers was a prerogative of those entrusted with producing knowledge in universities because they produced knowledge for the public good, not for private purposes.

Academic freedom brings with it obligations. To gain and exercise academic freedom, researchers are required to "be trained and credentialed according to the rules of their disciplines; without such training their 'science' would have no legitimacy." The regulation of professions by those already qualified was recognized as the key guarantee of legitimacy, the ultimate determinant of the authority for academic freedom. Professional associations were described as "an organized society of truth-seekers" that "set standards of inquiry and assessed the validity (the apparent scientific quality or truthfulness) of the ideas offered." In 2021, every disciplinary society to which an anthropological researcher can belong in North America endorses as part of its principles of research conduct the need to engage with, and respect, the communities that provide the substance of our analyses. Far from being inconsistent with academic freedom, commitments to communities are central to our responsible conduct of research, an obligation we assume by virtue of being part of our discipline.

Yet this observation faces a challenge: Weiss and Springer claim that disciplines and individuals accepting the responsibility for collaboration are abandoning the goals of scientific progress, which they identify with a number of attributes: objectivity, empiricism, and positivism. This model of science seems to be limited to the formulation and testing (or refutation) of hypotheses in which only empirically observable forces can be treated as potential causes. Described as "the scientific method," the equation of research inquiry with these specific ways to conduct science reflects what Hanne Andersen and Brian Hepburn describe as a public, non-specialist view that is countered by the conclusion reached in philosophy of science "that there is not any unique, easily described scientific method." The

\footnotetext{
${ }^{2}$ Joyce 2002, 99-100 (emphasis added).

${ }^{3}$ Weiss and Springer 2020.

${ }^{4}$ Scott 2009.

${ }^{5}$ Scott 2009, 459 .

${ }^{6}$ Scott 2009,460 .

${ }^{7}$ Andersen and Hepburn 2020, 6.1.
} 
repeated claim made in Weiss and Springer's book for a defense of scientific method recalls Andersen and Hepburn's comment that "[p]hilosophical positions that argue for a simple and unique scientific method ... have often attracted practitioners who felt that they had a need to defend their domain of practice. ${ }^{8}$

We could address the stasis in thinking and interjection of out-of-date and disingenuous arguments represented by this volume in multiple ways. As a museum professional myself, I was tempted to respond to the exaggerated claim that there will soon be no collections available for research and the argument that there are no benefits from research consultation about collections-based research. In a world where engagement with source communities in museums is leading to new insights about the significance of collections, this claim rings quite hollow. Yet it seemed to me that other voices could speak as well to these questions as I could. ${ }^{9}$ Another approach would be to contest the central claim made that the production of knowledge through study of biological materials is being impeded or made impossible by the practices that the book's authors portray as unique to repatriation. I leave the task of explaining how research continues to others with expertise in bioarchaeology, including members of the affected communities who are themselves professionally trained practitioners. $^{10}$

What I was left with was the need to confront the central argument that the very goal of producing reliable knowledge through a shared and publicly responsive method that we might recognize as science is endangered by changes that NAGPRA demands. As has ever been true, some research questions will be pursued, and others will not be; scientists do not actually have a right to conduct research on any topic in any way they wish. The responsible conduct of research, in fact, does call for consideration of the harm that can be done to a subject population. It asks us to weigh the potential benefits against the harms. Where Weiss and Springer's book complains that some genetic research will be stopped because it might stigmatize community members, and expresses dismay that one of the considerations a community might take in agreeing to, or declining, research is the potential impact on land and water rights, these are precisely the kind of concerns that researchers today are required to take into account across disciplines. Insisting that some topic is of interest to the researcher is insufficient grounds to allow potentially harmful work to proceed. Denying the harm because the researcher does not share the beliefs of the subject population is insufficient justification for proceeding with research a community has declined to allow. Claiming to speak for universal knowledge does not allow a researcher in the twenty-first century to reclaim a position of power to conduct research without constraints.

Yet, even here, trying to respond to the book is frustrating. Beyond simply being uninformed by several decades of actual progress, the claim that repatriation will destroy (or is destroying) the possibility to conduct scientific research, while foundational for the book, is never made in an entirely clear or coherent way. The elements of the argument are fundamentally four claims. First, science as defined here is a search for truth; in the case of historical studies like archaeological or bioarchaeological research, this is a search for a singular narrative about the past. Second, this kind of science proceeds by something repeatedly referred to as "the scientific method," which is never explicitly defined but associated with positivism and a particular cycle of repeated data recording (in some places, presented as requiring continued access to originally measured samples and, thus, permanent retention of collections). Third, this preferred form of science supposedly precludes

\footnotetext{
${ }^{8}$ Andersen and Hepburn 2020, 6.2.

${ }^{9}$ See Wendy Teeter, Desiree Martinez, and Dorothy Lippert, "Creating a New Future: Redeveloping the TribalMuseum Relationship in the time of NAGPRA," in this issue.

${ }^{10}$ Siân Halcrow et al., "Moving beyond Weiss and Springer's Repatriation and Erasing the Past: Indigenous Values, Relationships, and Research," in this issue.
} 
giving greater weight to the perspectives of one person or group of people - although exceptions appear to be allowed for the singular scientific expert, whose authority does seem categorically to outweigh any other form of knowledge. The fourth claim made is that this model of science cannot submit to any form of prior constraint, which is described as censorship, self-censorship, suppression, and modulation of inquiry. While the first three claims are familiar, if outdated, the fourth aligns with few others, as the history of science in the twentieth century is, in part, a history of balancing research goals against social needs and potential harms.

While Weiss and Springer do a very poor job of making a coherent argument for their position, we can use their publication as an inspiration to revisit some of the broader principles of responsible conduct of research. The National Institutes of Health propose that following such practices produces "a research environment that enables scientists to work together toward common goals, and promotes public confidence in scientific knowledge and progress for the public good." 11 While Weiss and Springer portray the implementation of NAGPRA and the changes that followed as being without parallel, we can see NAGPRA and other related voluntary national and international efforts as part of the development of broader practices of responsible conduct of research, which include a variety of ways that researchers submit to prior clearance of research (derided in this book as "licensing and censorship") through such things as permitting processes, reviews of impacts on human subjects, and even submission to peer review in grant proposal competitions and publishing.

Science is generally understood in the contemporary world as having the potential to produce unintended negative effects and is simply not an open-ended practice ruled by the will of the scientist. This view of science in the twenty-first century could be illustrated by any number of studies that conclude that "researchers' rights to pursue an interesting hypothesis, and their freedom of expression, are conditional." 12 The conditional nature of research is based on "practical and ethical principles that establish real boundaries for the permissibility of certain programs of research," a combination of the limits that may be placed on researchers by others, and the "responsibilities a researcher assumes when pursuing a program of study." 13 David Pittenger identifies the protection of participants (familiar as protection of human subjects) and the value of knowledge weighed against potential harm to a community as well-established bases of limitation on research freedom. He cites other researchers arguing that "scientists should be responsible for the consequences of their research and they should inform the public about those consequences." ${ }^{14}$ Particular debate exists in the contemporary world about where a distinction should be drawn between scientific freedom as a form of freedom of speech and scientific practice as engaged action that may require greater scrutiny and merit considerable regulation. A central distinction between observation and manipulation, and a concern about potential conflicts between scientific freedom and "human dignity," have been identified as central to understanding science in the contemporary world. ${ }^{15}$

In 1999, I described the view of research interests balanced against the interests of the community under study using then-current language about the multiple kinds of stakes involved in potential research. The diverse interests involved do not allow for one of the interested parties (scientists) to claim unilateral decision-making power. Relying on analyses by philosopher Alison Wylie of the concept of "stewardship" employed in the code of

\footnotetext{
${ }^{11}$ NIH 2020.

12 Pittenger 2003, 105.

13 Pittenger 2003, 110.

${ }^{14}$ Pittenger 2003, 119.

${ }^{15}$ Santosuosso, Sellaroli, and Fabio 2007.
} 
ethics of the Society for American Archaeology, ${ }^{16}$ I identified a contradiction between stewardship as responsibility and stewardship as a claim of authority. Weiss and Springer understand scientists as having the authority to determine what questions should be asked, how they should be addressed, and how the proposed interpretations should be disseminated. Yet, as I already noted in 1999, this was not the actual state of research. Constraints on research questions extend throughout science - from the peer reviewers who decide what research is funded, to those controlling access to sites (whether landowners, government agencies, or communities), to the labs that decide which analyses might be carried out using limited time and resources, to the reviewers who decide what articles and books are worthy of publication. Added to these fundamental processes of constraint are others that come into play legally - permits, approvals for destructive analysis of materials, and, yes, prior approval before publication - where governments or contracting agencies control the process. From this perspective, what NAGPRA did was not unprecedented; it extended to a previously excluded set of interested parties a voice in research like that already claimed by research sponsors, permitting agencies, contracting clients, and government jurisdictions.

NAGPRA, of course, does more than this. It recognizes moral rights that descendant groups have with respect to their own ancestral dead. It is in this sense that NAGPRA is often characterized as human rights law. NAGPRA addresses the fact that, due to political histories of dispossession and forcible removal of rights of self-determination, and often through specific incidents of deadly violence, Native American communities have seen their own dead converted into specimens controlled by outside groups. The use of the remains of Native American ancestors without the consent of their families was addressed in the law by recognizing a community interest in the respectful treatment of the dead. This consideration is portrayed in Weiss and Springer's book as requiring an unconstitutional establishment of a religious preference. Yet legal scholars like Fred Smith argue that this recognition is consistent with US law respecting the continued potential for harm to be done to human beings after their death, law that has historically been inconsistently applied based on race, economic marginalization, and social power. ${ }^{17}$

A final argument of Weiss and Springer's book, which is oddly dominant throughout, is a specific claim that consideration of evidence that the authors identify as "religion" (such as oral historical or folkloric evidence, specifically allowable among other lines of evidence when determining cultural affiliation in NAGPRA) is incompatible with the creation of valid knowledge. This argument is advanced by conflating all oral narrative traditions with religion. But the inclusion of oral history in NAGPRA is intended to amplify understanding in situations where documentary historical sources do not exist. Anthropological archaeologists actually have substantial experience in employing sources of information like this in order to understand histories that were not written using scripts. This expertise is never acknowledged. Instead, all oral narratives are treated disdainfully, as if they suffer from a lack of first-hand testimony. The view of historical documents that is evident is surprisingly naive. For anyone who conducts archival research - as I do - one of the first things you learn is that documents present narratives told from the perspective of interested parties whose causal explanations cannot be simply taken as facts.

The greatest flaw in Weiss and Springer's book is, ultimately, its equation of science with a search for "truth" rather than seeing science as a means to a never-ending pursuit of knowledge. Over generations, commentary on academic freedom and its relationship to disciplinary standards has stressed that it is knowledge that scholars produce, not truth.

\footnotetext{
${ }^{16}$ Wylie 1996.

${ }^{17}$ Smith 2020.
} 
"Even after prolonged examination and testing, the claim [to truth] can be accorded only a high degree of probability," wrote social scientist Glenn Morrow in $1968 .{ }^{18}$ When we replace the erroneous claim that science discovers truth with a more suitably humble admission that what we do is create knowledge, the effect of accepting dialogue with others about our research questions, methods, and conclusions is made clearer: it leads to improvement in knowledge.

Centrally, engaging with people from outside disciplinary comfort zones should have the positive effect of forcing each of us to reexamine our own biases and recognize them - a key aspect of moving toward an aspirational goal of science - to be objective. Weiss and Springer seem unfortunately to subscribe to an uninformed view in which objectivity is achieved by being suspended outside the world of human connections. That form of objectivity is not attainable in social and historical sciences. While a chemist can seek to limit their intervention in experimental reactions, a human scientist analyzing human history, behavior, and values cannot eliminate their human presence in the situation. Scott, in her historical account of academic freedom, gives us a telling example. In the struggle to improve knowledge in her own discipline of history, expansion of the viewpoint of history to encompass a wider array of subject positions was critical to the creation of women's history, African American history, and other approaches where a historian might "bring different perspectives to her work." She recounts the backlash accusing such scholars of "politicizing history by exposing the ways in which standards of exclusion effectively discriminated on the basis of gender or race." Their opponents claimed to be "defending the terrain of disinterested history" and accused them of "substituting ideology for scholarly rigor." 19

The events that Scott comments on took place decades before her essay was published in 2009. Yet they model precisely the fundamental charge made by the authors of this book: "[T] evidence were unequivocal and otherwise presented no problems about the position, point of view, and interpretations" of scholars. ${ }^{20}$ What these critics once derided as destructive demands that researchers take other perspectives into account have produced, in contemporary history, stronger and richer accounts of the past. The parallel demands made on anthropology - that it engage with perspectives of the people under study - have also opened up new avenues for the production of knowledge. The fact that some studies can no longer be carried out as they would have been in the past does not portend an end to science. It simply signals the maturation of anthropological research and its acceptance of social and ethical responsibilities that come with academic freedom. There are topics for debate in this arena. But they are not the ones exposed by Weiss and Springer in Repatriation and Erasing the Past, which is so sadly uninformed by decades of commentary in legal scholarship, research ethics, and philosophy of science.

\section{Bibliography}

Andersen, Hanne, and Brian Hepburn. 2020. "Scientific Method." In The Stanford Encyclopedia of Philosophy, edited by Edward N. Zalta. Stanford, CA: Stanford University Press. https://plato.stanford.edu/archives/win2020/entries/ scientific-method (accessed 17 May 2021).

Joyce, Rosemary A. 2002. "Academic Freedom, Stewardship and Cultural Heritage: Weighing the Interests of Stakeholders in Crafting Repatriation Approaches." In The Dead and Their Possessions: Repatriation in Principle, Policy and Practice, edited by Cresside Fforde, Jane Hubert, and Paul Turnbull, 99-107. London: Routledge.

National Insitutes of Health. 2020. "Responsible Conduct of Research Training." https://oir.nih.gov/sourcebook/ ethical-conduct/responsible-conduct-research-training (accessed 16 May 2021).

\footnotetext{
${ }^{18}$ Cited in Scott 2009, 460-61.

19 Scott 2009, 462.

${ }^{20}$ Scott 2009, 462-63.
} 
Pittenger, David J. 2003. "Intellectual Freedom and Editorial Responsibilities Within the Context of Controversial Research.” Ethics and Behavior 13, no. 2: 105-25.

Santosuosso, Amedeo, Valentina Sellaroli, and Elisabetta Fabio. 2007. "What Constitutional Protection for Freedom of Scientific Research?" Journal of Medical Ethics 33, no. 6: 342-44.

Scott, Joan. 2009. "Knowledge, Power, and Academic Freedom." Social Research 76, no. 2: 451-80.

Smith, Fred O. 2020. "The Constitution after Death." Columbia Law Review 120, no. 6: 1471-1548.

Weiss, Elizabeth, and James W. Springer. 2020. Repatriation and Erasing the Past. Gainesville: University of Florida Press.

Wylie, Alison. 1996. "Ethical Dilemmas in Archaeological Practice: Looting, Repatriation, Stewardship, and the (Trans)formation of Disciplinary Identity." Perspectives on Science 4: 154-94.

Cite this article:Joyce, Rosemary A. 2021. "Science, objectivity, and academic freedom in the twenty-first century." International Journal of Cultural Property 28, no. 2: 193-199. https://doi.org/10.1017/S0940739121000230 